\title{
Ulnar taraflı el bileği ağrısında muayene ve tanı
}

\section{Examination and diagnosis of ulnar sided wrist pain}

\author{
Gökçe Yıldıran, Nebil Selimoğlu \\ Konya Şehir Hastanesi, El Cerrahisi Kliniği, Konya
}

\begin{abstract}
Ulnar taraflı el bileği ağrıları, üst ekstremite fonksiyon kısıtlılıklarının yaygın nedenlerindendir. Ulnar taraf el bileği, iç içe geçmiş karmaşık bir anatomik yapıya sahip olduğundan ayırıcı tanı önem arz etmektedir. Bu ayırıcı tanıya giden yolda hastadan alınan anamnez, elin tam bir fizik muayenesi ve bunlara eşlik eden görüntüleme yöntemleri altın değerindedir. Anamnezde hastanın uğraşıları, baskın eli, ağrının zamanı, süresi, şiddeti ve eşlik eden belirtiler sorgulanmalıdır. Gözle muayene, eklem açıklığı, palpasyon, vasküler ve nörolojik muayene karşı taraf el ile kıyaslanarak yapılmalıdır. Fovea bulgusu, Grind test, ballotman testi, ulnokarpal stres test, midkarpal şift testi de ulnar taraf el bilek ağrılarındaki muayeneyi tamamlayıcı spesifik testleri oluşturur. Ayırıcı tanıda radyokarpal ve midkarpal lokal anestezik enjeksiyonları yardımcı olabilir. Kemik patolojiler (hamat kırığı, pisiform kırığı, ulna stiloid kırığı, beşinci metakarp bazis kırığı), triangular fibrokartilaj kompleks, radyoulnar eklem (radyoulnar eklem instabilitesi, ulnokarpal sıkışma sendromu), karpal instabiliteler (trikuetrolunat instabilite, midkarpal instabilite), vasküler (hipotenar el sendromu), nörolojik (Guyon kanalında ulnar sinir tuzaklanması, ulnar dorsal duyu sinir nöriti), tendon (ekstansör karpi ulnaris, fleksör karpi ulnaris) ile ilişkili patolojiler ayırıcı tanıda düşünülmesi gereken hastalıkları oluşturur.
\end{abstract}

Anahtar sözcükler: ağrı; el bileği; provokatif test; ulnar taraf
Ulnar sided wrist pain is one of the common causes of upper extremity functional limitations. Since the ulnar side wrist has a complex anatomical structure, differential diagnosis is important. On the way to this differential diagnosis, the anamnesis of the patient, a complete physical examination of the hand and the accompanying imaging methods are crucial. In this article, it is aimed to present the details of the examination required for this differential diagnosis. In the anamnesis, the occupations of the patient, the dominant hand, pain characteristics, pain duration, severity of the pain, and accompanying symptoms should be questioned. Inspection, range of motion, palpation, vascular and neurological examination should be performed by comparing the opposite side with the hand. Foveal sign, Grind test, ballotment test, ulnocarpal stress test, midcarpal shift test also constitute specific tests that complete the examination of ulnar side wrist pains. Radiocarpal and midcarpal local anesthetic injections may be helpful in the differential diagnosis. Osseous pathologies (hamate fracture, pisiform fracture, ulna styloid fracture, fifth metacarpal basis fracture), triangular fibrocartilage complex, radioulnar joint (radioulnar joint instability, ulnocarpal impingement syndrome), carpal instability (triquetrolunate instability, midcarpal instability syndrome), neurological (ulnar nerve entrapment in the Guyon canal, ulnar dorsal sensory nerve neuritis), tendon (extensor carpi ulnaris, flexor carpi ulnaris) related diseases should be considered in differential diagnosis.

Key words: pain; wrist; provocative test; ulnar-sided
U Inar taraflı el bileği ağrıları, üst ekstremite fonksiyon kısıtlılıklarının yaygın nedenlerindendir. Ulnar taraf el bileği, iç içe geçmiş anatomik yapılanma, karmaşık ayııcı tanısı ve tedavi sonuçlarının değişkenliği nedeni ile el bileğinin kara kutusu olarak adlandırılmıştır. ${ }^{[1]}$ Teşhise giden yolda muayene altın değerinde olup bu yazıda anamnezden muayeneye, spesifik provokatif testlerden görüntüleme yöntemlerine dek teşhis yolundaki basamaklardan söz edilmiştir.
Ayırıcı tanıda radyokarpal ve midkarpal lokal anestezik enjeksiyonları yardımcı olabilir. Manyetik rezonans (MR) görüntüleme anormallikler gösterebilir, ancak nispeten spesifik değildir. MR artrografide kontrast maddenin geçişi ile triangular fibrokartilaj kompleks (TFKK) ve lunotrikuetral (LT) bağ yaralanmaları daha ayrıntılı incelenebilmektedir. Artroskopi ile doğrudan değerlendirme, tanı ve tedavide altın standart olmaya devam etmektedir.

\footnotetext{
- Illetişim adresi: Op. Dr. Gökçe Yıldıran, Konya Şehir Hastanesi, El Cerrahisi Kliniği, Konya

Tel: 0536 - 4882974 e-posta: ggokceunal@gmail.com

- Geliş tarihi: 12 Mayıs $2021 \quad$ Kabul tarihi: 24 Mayıs 2021
}

ORCID iD: Gökçe Yıldıran, 0000-0002-8587-1125 • Nebil Selimoğlu, 0000-0002-0769-1532 


\section{Anamnez}

Ulnar taraflı el bilek ağrılarında altta yatan sebebi bulabilmek için anamnez çok önemli bir basamaktır. Hastanın baskın eli, mesleği, uğraşıları, geçirilmiş yaralanmalar etiyolojiyi belirlemeye yardımcı olabilir. Hastanın mesleği ve uğraşılarında tekrarlayan hareketlerin mevcudiyeti not edilmelidir.

Şikâyeti derinlemesine sorgulayarak ne zamandır mevcut olduğu, artıran ya da azaltan faktörlerin neler olduğu öğrenilmelidir. Eşlik eden “klik” sesi, duyu değişiklikleri, el becerilerinde azalma ve eklem sertlikleri olup olmadığı sorgulanmalıdır. Yaralanma mekanizmasının ayrıntıları öğrenilmelidir, çünkü patolojiye ilişkin çok önemli ayrıntılar anamnezden bulunabilir. Örneğin distal radyoulnar eklem (DRUE) ve triangular fibrokartilaj kompleks yaralanmaları el bileği aşıı pronasyonda aksiyel yüke maruz kaldığında meydana gelir. ${ }^{[2]}$ Ağrının şiddeti, gün içindeki yoğunluğu ve uyuşukluk semptomları sorgulanmalıdır.

Önceden geçirilen ameliyatlar ile geçirilen travmalar hakkında bilgi alınmalıdır. Mevcut şikâyetine yönelik medikal ve cerrahi tedaviler, enjeksiyonlar, ergoterapi ve fizyoterapiler ile bu tedavilere alınan yanıt sorgulanmalıdır.

El ve el bilek bölgesi ile ilgili tüm şikâyetlerin öyküsü sorgulandıktan sonraki önemli bir basamak da boyun ağrısının olup olmadığıdır. Radikülopatiye neden olan bir spinal dejeneratif değişiklik de şikâyetin kaynağı olabilir. Hastanın başka eklemlerindeki ağrıları da göz önünde bulundurulmalıdır. Ulnar taraflı el bilek ağrısı, aslında enflamatuvar artriti olan bir hastanın başvuru şikâyeti olabilir.

\section{Muayene}

Genel olarak el ve el bilek muayenesinde her iki tarafın kıyaslanması önemlidir. Bu kural, ulnar taraflı el bilek ağrıları için de geçerlidir.

Gözle muayenede karşı tarafla simetri kıyaslaması yapılabilir, atrofi, eritem, ödem, siyanoz gözlenebilir. Örneğin hipotenar atrofi, Guyon kanalında veya daha proksimalde ulnar sinirin tuzaklanmasını düşündürür. Gözle muayene pek çok patolojiyi ortaya koyabilir: Ganglionlar, sinovitler, tümörler, kas atrofileri, psöriyatik plaklar, dirsekteki romatoid nodüller ile önceden geçirilmiş cerrahi ve travma izlerine de dikkat edilmelidir.

Eklemin aktif ve pasif hareket açıklığı karşı taraf ile kıyaslanarak değerlendirilmelidir. El bileği hareket açıklığı değerlendirilirken karşı elin yaptığı baskı nedeniyle gerçek kısıtlı eklem hareket açıklığının maskelenmemesi için her iki elin birbirine temas ettirilmeden de el bileği eklem hareket açıklığının ölçümlenerek karşı el ve el bileği ile kıyaslanması da muayenede bir seçenektir. ${ }^{[3]}$ Fleksiyonekstansiyon, radyal-ulnar deviasyon, pronasyon-supinasyon olarak üç plandaki hareketler ve sirkumdiksiyon hareket açıklıkları her iki el ve el bileği için de değerlendirilmelidir. Bu basamak bir tanıya ulaşmak için elzem olmasa da problemin potansiyel ciddiyetini anlamak için ve müdahalelerden sonra hastadaki değişiklikleri takip edebilmek için önemlidir. Bunun yanında eklem açıklıklarının değerlendirilmesi, distal radyoulnar eklemin ve ekstansör karpi ulnaris (EKU) tendonunun instabilitesini ortaya çıkarabilir. Bu nedenle EKU tendiniti de muayene edilmelidir, ulnar deviasyonda zorlu bilek ekstansiyonu esnasında tendon hattı üzerinde ağrı ortaya çıkması, tendiniti düşündürür.

El ile muayeneden önce hastaya ağrısının tam olarak nerede olduğunun sorulması önemlidir, ayırıcı tanı bu noktada başlar. Ayırıcı tanı için sistematik bir muayene gerekir; ulnar taraf el bilek ağrısı olan hasta için radyal taraftan muayeneye başlamak ve ulnar tarafa gelindiğinde ağrının kaynağını lokalize etmek için bazı noktalar üzerinde durulması önemlidir. Örneğin hamat kancası üzerindeki hassasiyet hamat kanca kırığını veya kaynamamasını düşündürür. Hamat kanca kırı̆̆ı yalnızca kırık semptomları ile bulgu verebileceği gibi Guyon kanalında ulnar sinire bası yaparak ulnar sinir motor ya da mikst tip bası bulguları da yaratabilir.

Vasküler muayenede radyal ve ulnar arterlerin atımlarına bakılmalı, Allen testi yapılmalıdır. Allen testinde, hasta yumruğunu birkaç kez sıkıp kapattığında her iki arter de el bileği seviyesinde baskı uygulanarak kapatılır, hasta elini açtıktan sonra arterlerden biri açılarak eli kanlandırması değerlendirilir. Normal bir kollateral dolaşım varlığında 5 sn civarında olan sürenin 10 saniyeyi aşması durumunda test pozitif kabul edilir. Literatürde testin \%5 yanlış negatif sonuç verdiği bildirilmektedir. Ulnar arterdeki tromboz da ulnar taraflı ağrı ve soğukluk ortaya çıkarabilir. Palmar bölgeyi çekiç gibi tekrarlayan hareketler ile kullanmak sonucunda ulnar çekiç sendromu ya da hipotenar çekiç sendromu olarak anılan ulnar arter trombozu meydana gelebilir.

Nörolojik muayenede radyal, ulnar ve median sinir dağıımı dikkatle incelenmelidir. İki nokta ayrımı (diskriminasyonu) bu muayeneye dâhil edilebilir. Ulnar taraflı el bilek ağrıları için ulnar sinirin duyu ve motor muayenesi dikkatle yapılmalıdır. Ulnar sinirin dorsal duyu dalının muayenesinde hassasiyet, ağrı, Tinnel bulgusu varlığı muayene edilmeli, duyu kaybı alanı belirlenmelidir. Motor muayenede ekstansör karpi ulnarisin hareketleri de muayene edilmeli, olası tendinitler gözden kaçırılmamalıdır.

Palpasyon proksimalden distale doğru da yapılabilir ve distal ulna ve radyoulnar eklemden başlanır. Aşırı pronasyon yaralanması sonrası triangular fibrokartilaj kompleks ve distal radyoulnar eklem dorsal kapsülü hasarlanarak distal radyoulnar eklem dorsal dislokasyonuna sebep olabilir. Bu da el bileği dorsalinde çıkıntı ile ve ön kol pronasyonda kilitlenmiş şekilde bulgu verir. ${ }^{[2]}$ 


\section{Fovea bulgusu}

Fovea bulgusunun pozitif olması, TFKK patolojisine işaret eder (Şekil 1). Foveadaki problemler ve ulnotrikuetral bağ yaralanmaları için spesifiktir. ${ }^{[4]}$ Fovea bulgusunda, ulna stiloidi, fleksör karpi ulnaris tendonu ve pisiform kemik arasındaki yumuşak noktaya başparmak ile basmak ağrıyı ortaya çıkarır (Şekil 2).

Karpal kemiklerin muayenesinde lunatum, trikuetrum ve pisiform kemikler özellikle incelenmelidir. Azalmış eklem hareket açıklığı ile lunat kemik üzerinde hassasiyet Kienböck hastalığını işaret eder. ${ }^{[5]}$ Kienböck hastalığı negatif ulnar varyans ve azalmış radyal inklinasyon gibi biyomekanik faktörlere ve lunat kemiğin kanlanması ve geometrisi gibi anatomik faktörlere bağlı lunat kemikteki avasküler nekrozdur. Sıklıkla baskın elde aktivite ile artan, dorsalde el bilek ağrısı mevcuttur. ${ }^{[6,7]}$ Radyokarpal eklem üzerinde hassasiyet ve azalmış kavrama kuvveti tespit edilebilir.

Trikuetrum üzerinde hassasiyet, laksite, lunotrikuetral eklem üzerinde atlama belirtileri lunotrikuetral bağda zorlanma veya yırtık bulgusu olabilir. Hamat kemik ise kapitat kemiğin ulnar tarafında yer alıp gövdesi dorsalden, çengeli volarden daha iyi palpe edilir.

\section{Grind testi}

Grind testi, pisiformu iki parmak arasında tutup trikuetruma yani dorsale doğru bastırırken ulnar ve radyal tarafa kaydırmaktır. Bu manevra ile ağrı olması pisotrikuetral eklemdeki dejeneratif değişikliklerin göstergesidir. Dört ve beşinci metakarp bazislerinin muayenesi ile tam kemik palpasyonu sonlandırılır.

Yumuşak dokuların muayenesinde EKU tendonu ulnar stiloid üzerindeki subluksasyon açısından incelenmelidir (Şekil 3). Çünkü altıncı dorsal kompartmana büyük kuvvetler uygulanır ve EKU bu noktada rüptüre olma riski altındadır.

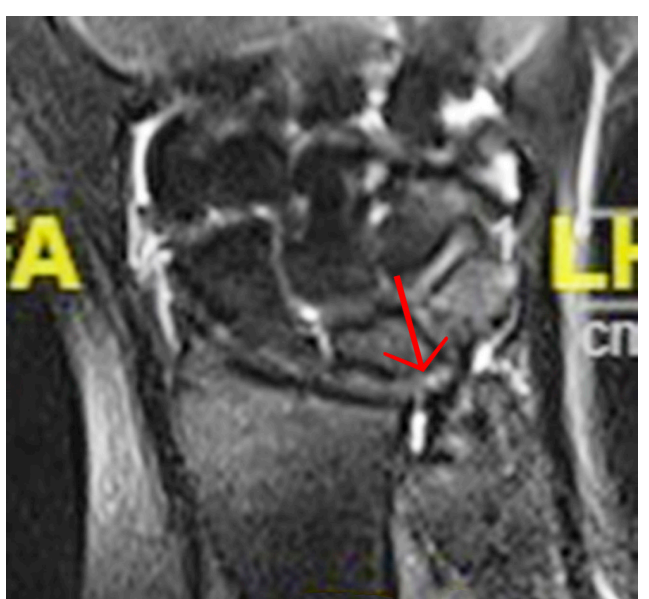

Şekil 1. T2 manyetik rezonans görüntülemede triangular fibrokartilaj komplekste yırtık (ok), kompleks devamlılı̆ında kesiklik ile tanınmaktadır.

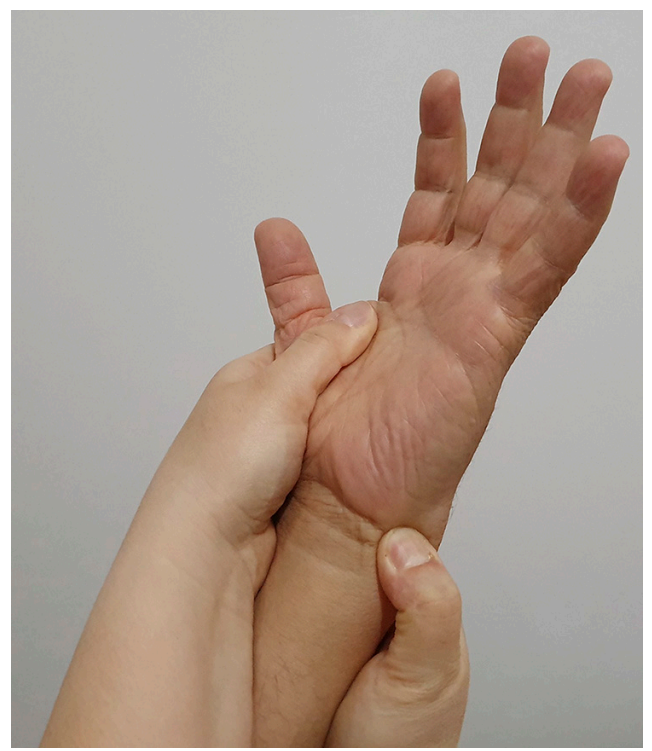

Şekil 2. Yumuşak nokta alanı; ulna stiloidi, fleksör karpi ulnaris tendonu ve pisiform kemik arasındadır, basmakla hassasiyet triangular fibrokartilaj kompleks yaralanmasını akla getirir.
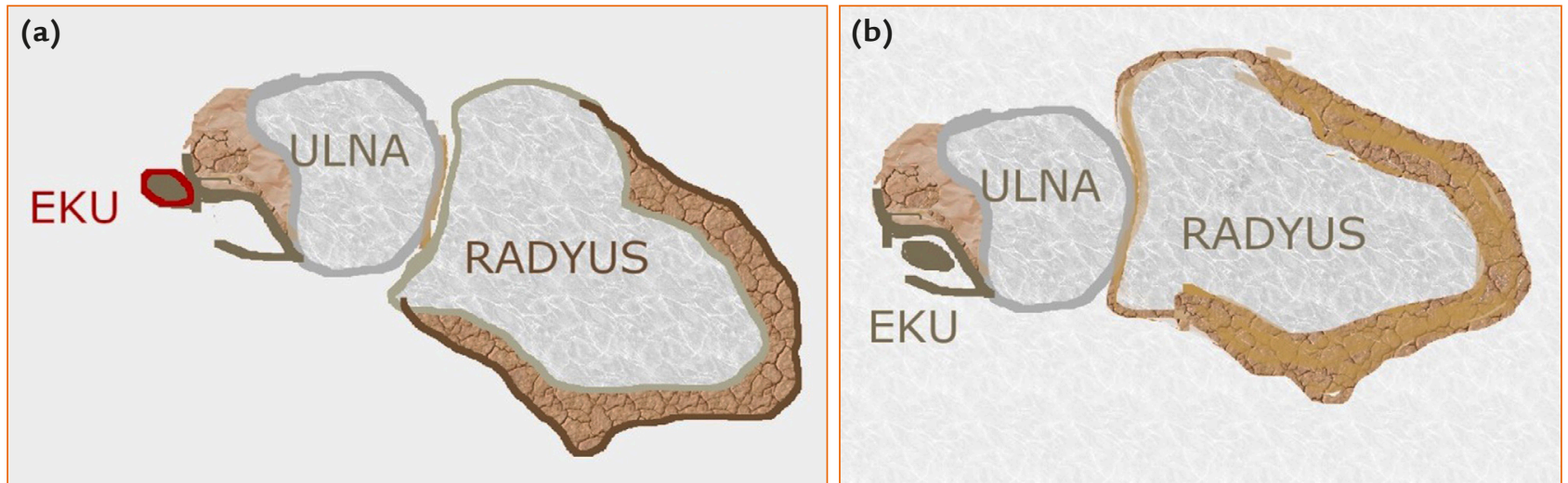

Şekil 3. a, b. Ekstansör karpi ulnaris tendonunun supinasyon hareketi ile dislokasyonu, aksiyel görüntü (a). Ekstansör karpi ulnaris tendonunun pronasyon hareketi ile yerine gelmesi, aksiyel görüntü (b). 
Diğer spesifik testler ulnar taraflı el bilek ağrılarında muayeneyi tamamlar ve karşı taraf el ve el bileği ile kıyaslanarak yapılmalıdır:

\section{Ekstansör karpi ulnaris (EKU) sinerji testi}

Ön kol pronasyonda ve aktif ulnar deviasyonda iken EKU tendonu ulnar stiloid ve beşinci metakarp bazisi arasındaki boşlukta palpe edilir. Dirençli hareketlerde hassasiyet ve ağrı olması tendinit bulgusudur. EKU sinerji testinde el bileği nötralde ve ön kol supinasyonda iken başparmağın dirençli radyal abduksiyonu sırasında izometrik bir kasılma olur. Bu esnada EKU ve fleksör karpi ulnaris tendonları el bileğini stabilize edebilmek için sinerjik hareket gösterir. Parmaklar tam ekstansiyonda iken bir el ile hastanın başparmak ve orta parmağı birbirine yaklaştırılırken diğer el ile EKU tendonu palpe edilir, hastadan dirence karşı başparmak abduksiyonu yapması istenir. Ulnar taraflı ağrı olması ile test pozitif kabul edilir. ${ }^{[8]}$

\section{Ulnokarpal stres test}

Nakamura ve ark. tarafından tanımlanmış provokatif bir testtir. ${ }^{\left[{ }^{9]}\right.}$ El bileği maksimum ulnar deviasyonda iken bileğe aksiyel yüklenme yapılmasıdır. Patolojinin varlığına duyarlı bir test olmakla birlikte ulnar impaksiyon sendromu, TFKK yırtığı, LT bağ yırtıklarında da pozitif belirti yaratabileceğinden çok spesifik bir test değildir. ${ }^{[10]}$ Bu nedenle eklem içi patolojilerinde tarama muayenesi olarak kullanılabilir.

\section{Ballotman testi}

Bu test, distal radyoulnar eklemin stabilitesini belirlemek için yapılır. El bileği nötral konumda iken başlanır, distal radius ve distal ulna her iki elin parmakları arasına alınır. Bir el radiusu stabilize ederken, ulna volar ve dorsal yönde hareket ettirilir (Şekil 4). El bileği radyal deviasyona getirildiğinde el bileğinin ulnar tarafındaki yapılar gerilir ve ulna hareketinin bir miktar kısıtlanması beklenir. Distal radyoulnar eklemdeki instabilite en yaygın olarak sigmoid çentiği de içeren distal radius kırıkları ile ilişkilidir. TFKK, distal radyoulnar eklemin önemli bir stabilizatörüdür ve yırtıklarında instabilite meydana gelebilir.

\section{Midkarpal şift testi}

Midkarpal instabiliteyi araştırır. Hastanın ön kolu $15^{\circ}$ ulnar deviasyon ve pronasyonda stabilize edilir. Başparmak kapitatın distal tarafına yerleştirilir, volar basınç uygulanırken metakarplara aksiyel yük uygulanır. Ağrılı tıklama pozitif test bulgusu olarak kabul edilir.

\section{Triangular fibrokartilaj kompleks (TFKK) yüklenme testi (TFCC load test)}

Bileğin ulnar deviasyonda aksiyel yüklenmesi ile volar-dorsal olarak hareket ettirilmesi veya ön kolun

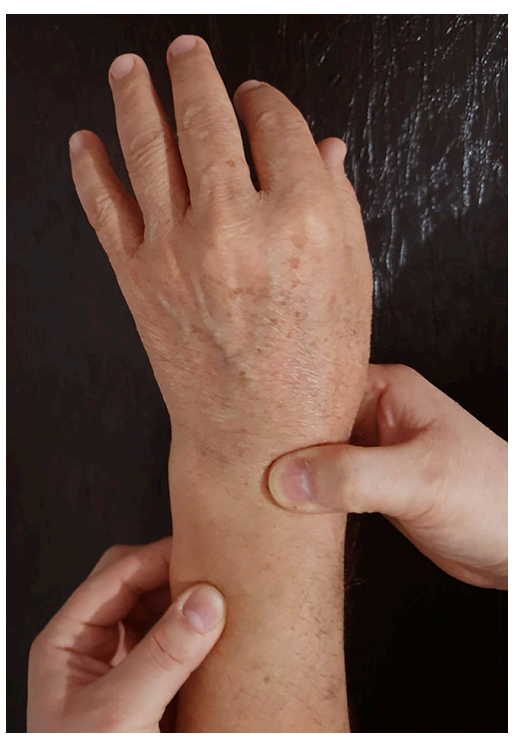

Şekil 4. Ballotman testi: Distal radius ve distal ulna her iki elin parmakları arasına alınır. Bir el radiusu stabilize ederken, ulna volar ve dorsal yönde hareket ettirilir.

döndürülmesi ile yapılır. Ağrı veya tıklama ile test pozitif kabul edilir. Pozitif varyansa sahip bir ulna ile trikuetrum arasında TFKK'nin sıkışmasını içeren bir durum olan ulnokarpal impaksiyon bu bölgede hassasiyete sebep olabilir. ${ }^{[8]}$

\section{Baskı testi (Press test)}

TFKK yırtıklarını tespit etmek için yapılan basit bir provokatif testtir. Oturan hastanın etkilenen bileğe dayanarak sandalyeden kendini kaldırması ile aksiyel yüklenme yaratıldığında hasta ulnar taraflı bir ağrı hisseder. ${ }^{[8]}$

\section{Piyano tuşu belirtisi}

Distal radyoulnar eklemde (DRUE) hassasiyet, DRUE artriti ile birlikte olan kararsızlık (instabilite) veya uyumsuzluktan kaynaklanabilir. Distal ulnar başın çıkıntısı DRUE dengesizliğinin bir işaretidir. Piyano tuşu belirtisi, DRUE instabilitesi ve TFKK yırtıkları için belirteçtir. Ön kol pronasyondayken ulnanın distal ucuna volar yönde hafif kurvet uygulanır. Bası kaldırıldığında ulna başı anatomik yerine dönüyorsa test pozitiftir. Ağrı ortaya çıkabilir (Şekil 5).

\section{Piyano tuşu testi}

Piyano tuşu işaretinin bir çeşidi olan piyano tuşu testi, DRUE instabilitesini değerlendirmek için kullanılır. Distal ulna pronasyon ve supinasyonun uç noktalarında volar ve dorsal yönde pasif olarak hareket ettirilir. Yaralanmamış tarafa göre ağrı, hassasiyet ve artan hareketlilik, DRUE instabilitesini gösterir. 


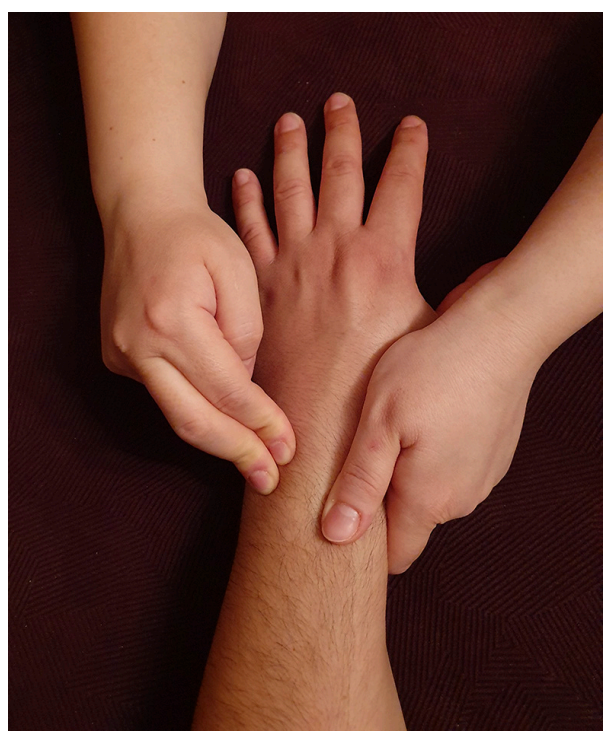

Şekil 5. Piyano tuşu belirtisi: Muayenede ulna başı volare itilir ve bırakıldığında geri gelir.

\section{Ulnar kompresyon testi/Distal radyoulnar eklem kompresyon testi}

Ulna başındaki radyal olarak yönlendirilmiş basıncın radiusun sigmoid çentiğine uygulanmasıdır. Distal radius ve ulna başı birbirine doğru bastırılır ve ön kol rotate edilir. DRUE artriti veya instabilitesi varsa, DRUE'nin sıkışması ağıı oluşturur. ${ }^{[8]}$

\section{Yer değiştirme testi}

Pronasyonda el bileğinin ulna üzerinde anteriordan posterior düzleme kayması ve yeniden normal hizalanmasını içeren bir testtir. Sublukse ulnar bileğin yerinin değiştirilmesi hastanın bilek ağrısını azaltırsa test pozitiftir.

\section{Pisiform destek testi}

Pisiformun palmar kısmına dorsal yönde basınç uygulanması tüm karpusun kalkmasına sebep olur. Bu testte ağrı veya tıklama meydana gelmesi, el bileğinin ulnar destek yapılarının tutulduğunu düşündürür.

\section{Lunotrikuetral kompresyon (Linscheid) testi}

Bu test, ikinci ve üçüncü karpometakarpal eklemlerin ligamentöz instabilitesini tespit etmek için kullanılır. Metakarp gövdeleri tek el ile desteklenir, metakarp başları dorsale ve palmara itilir. Ağrının karpometakarpal eklemlerde lokalize olduğu bir testtir (Şekil 6). ${ }^{[11]}$

\section{Ulnar enfiye kutusu testi}

Ulna başının distalinde ekstansör ve fleksör karpi ulnaris tendonlarının oluşturduğu olukta trikuetrum

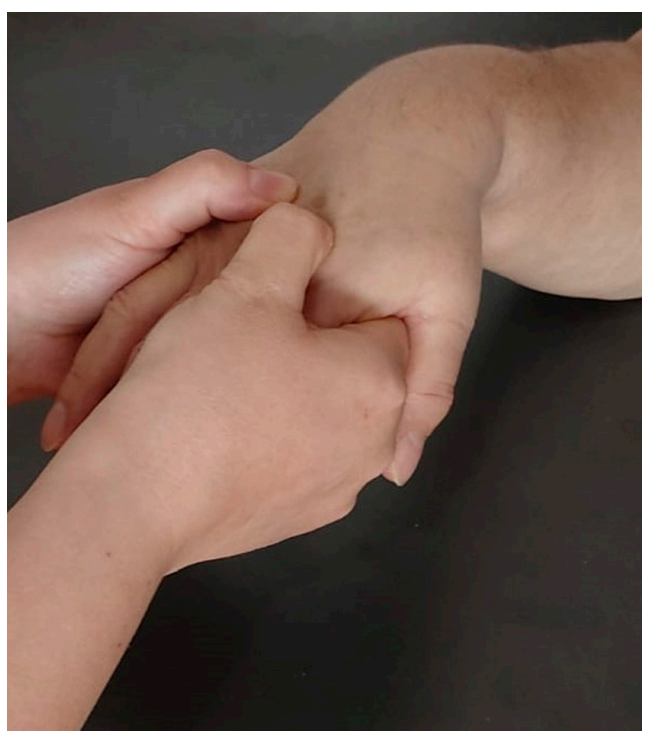

Şekil 6. Lunotrikuetral kompresyon (Linscheid) testi: Ağrı karpometakarpal eklemlerde lokalizedir.

üzerine lateral baskı uygulanmasıdır. Hastada ağrı oluşması, lunotrikuetral eklem instabilitesini düşündürür.

\section{Reagan ballotman testi}

El bilek nötralde iken bir elin başparmağı ve işaret parmağı ile lunat kemik sabitlenir. Diğer elin baş ve işaret parmağı ile kavranan trikuetrum ve pisiform volar dorsal yönde hareket ettirilir. Bu ön-arka yöndeki basınç ile ağrı, krepitasyon ve eklemde oluşan anormal deplasman, lunotrikuetral interosseöz bağın yaralanma olasılığını düşündürür (Şekil 7). ${ }^{[11]}$

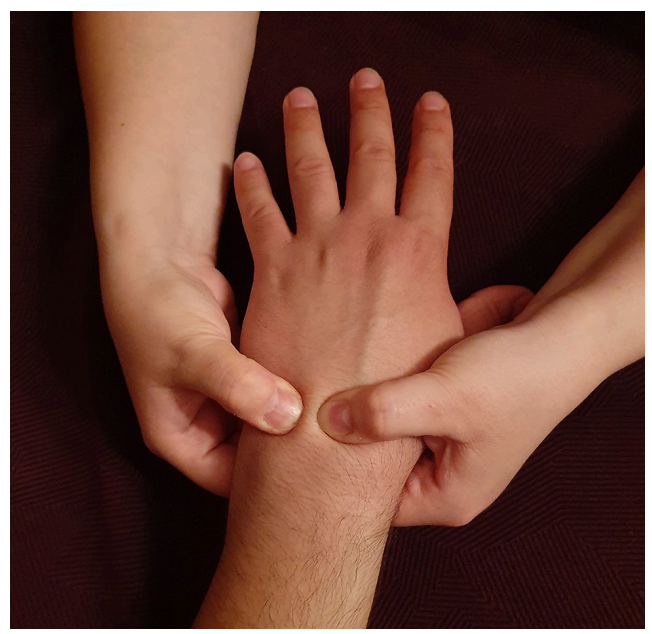

Şekil 7. Reagan ballotman testi: Lunotrikuetral interosseöz bağ yaralanmasını test eder. 


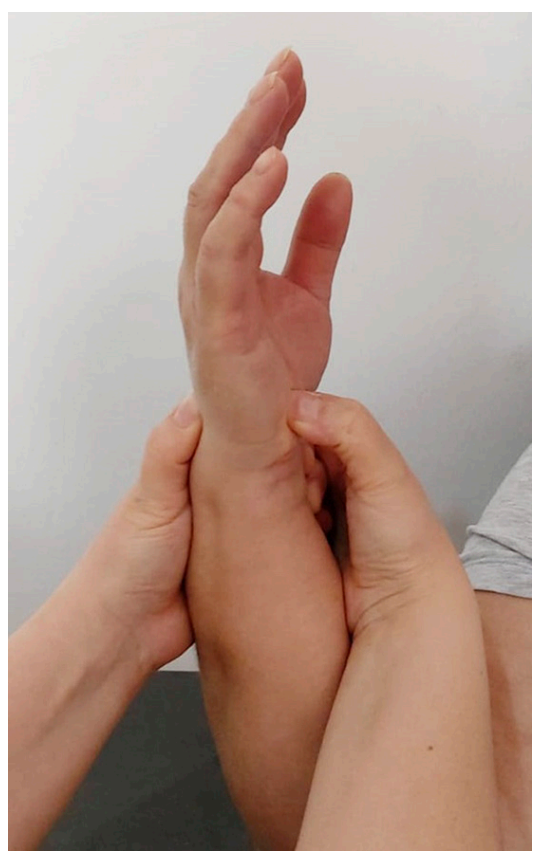

Şekil 8. Kleinman (makaslama) testi: Pisiform kemiği dorsale itmek lunotrikuetral eklemde ağrıya neden olur.

\section{Kleinman (makaslama) testi}

Muayene eden kişi hastanın karşısındadır, kontralateral başparmak lunat sırtının üzerinde, işaret parmağı pisiform üzerinde iken, başparmak ve işaret parmak birlikte sıkıştırılmaya çalışılır. Pisiform kemiği dorsale itilmesi ile oluşan makaslama kuvveti lunotrikuetral eklemde ağrıya neden olur (Şekil 8). ${ }^{[11]}$

\section{Pisotrikuetral makaslama testi}

Pisiformun triquetrum içine itilmesini içerir, ağrı veya krepitus olması halinde pozitiftir ve pisotrikuetral artriti gösterebilir. ${ }^{[8]}$

\section{Görüntüleme}

Tanıya yardımcı olacak görüntüleme yöntemleri içinde direkt radyografi ilk sıradadır. Hamat kanca kırığı, pisotrikuetral artrit, Kienböck hastalığı için tanıyı doğrulamada düz arka-ön grafiler, el bileği yan grafileri, karpal tünel grafileri gibi direkt grafiler yardımcıdır. Kienböck hastalığında lunat kollaps oturmuşsa bilgisayarlı tomografi nekrozun genişliğini ve trabekülar destrüksiyonu göstermede daha yararlıdır. Manyetik rezonans görüntüleme ise erken teşhiste en iyi seçenek olup ulnar impaksiyonu dışlar. Kienböck hastalığının ulnar impaksiyondan farkı lunat kemiğin bütününde ödem olmasıdır. Kienböck hastalığında genellikle santral dorsal bir el bileği ağrısı olsa da ulnar taraflı el bilek ağrılarının ayırıcı tanısında yer almaktadır.

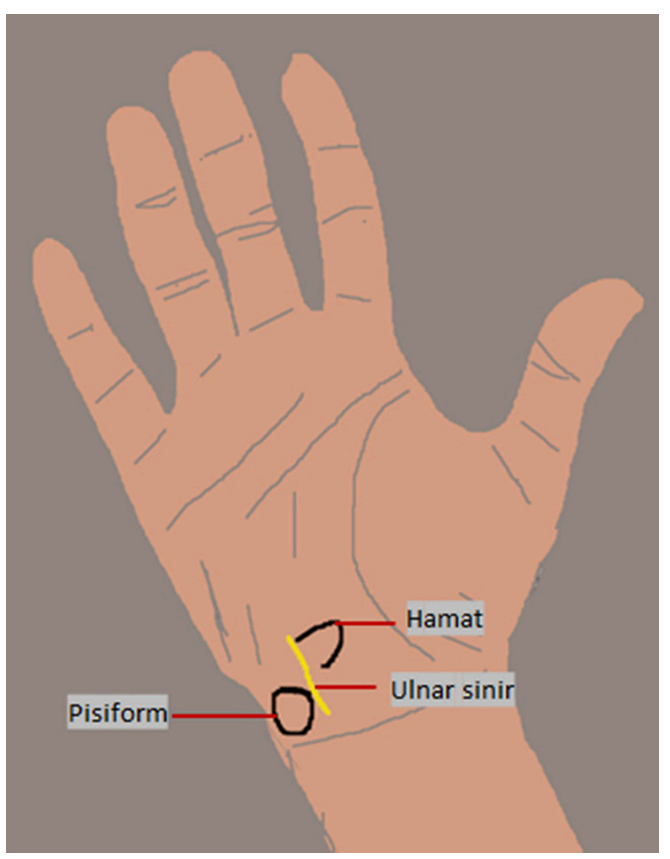

Şekil 9. Pisiform kırı̆̆ında ağrı Guyon kanalının anterolateralindedir.

Tüm bunlar bir araya toplandığında; ulnar taraflı el bilek ağrılarının ayırıcı tanısını osseöz patolojiler (hamat kırığı, pisiform kırığı, ulna stiloid kırı̆̆ı, beşinci metakarp bazis kırığı), TFKK, radyoulnar eklem (radyoulnar eklem instabilitesi, ulnokarpal sıkışma sendromu), karpal instabiliteler (trikuetrolunat instabilite, midkarpal instabilite), vasküler (hipotenar el sendromu), nörolojik (Guyon kanalında ulnar sinir tuzaklanması, ulnar dorsal duyu siniri nöriti), tendon (ekstansör karpi ulnaris, fleksör karpi ulnaris) ilişkili ağrılar oluşturur. ${ }^{[1,12]}$

\section{Hamat kırı̆gı}

Dört ve beşinci metakarplara aksiyel yüklenme ile ağrı artar. Pisiform radyalinde ve hamat kancasının $1 \mathrm{~cm}$ distalindeki noktada hassasiyet vardır. Hemen hemen tüm hastalar elin palmar bölgesinin ulnar tarafında veya el bileğinin dorsoulnar kısmında ağrıdan şikâyetçidir. En sık semptom ise kavrama ile artan ağrıdır. Bu nedenle kavrama gücü azalmıştır.

$15^{\circ}$ ters oblik görüntü alınması önerilir. Hamat gövde kırıkları, kanca kırıklarından daha sıktır ve rutin iki yönlü direkt grafilerde görülemeyebilir, bu nedenle bilgisayarlı tomografilere de başvurulur.

\section{Pisiform kırı̆̆ı}

Guyon kanalının anterolateral kısmını oluşturur (Şekil 9). $15^{\circ}$ supinasyonda ters oblik görüntü alınması 
önerilir. Genellikle düşme sonrası ulnar taraflı el bilek ağrısı ile semptom verir. Kavrama kuveti azalmıştır. Muayenede hipotenar şişlik ve hassasiyet mevcuttur. Diğer karpal kemiklerin ve distal radiusun kırı̆ı ekarte edilmelidir. Pisotrikuetral eklem en iyi $30^{\circ}$ el bileği supinasyonu ya da karpal tünel grafisi ile görüntülenir. Kırık paternini göstermek ve tedaviyi planlamak için bilgisayarlı tomografiler gerekebilir. Radyografilerde patoloji görülemezken karpal kırıktan yüksek şüphe duyuluyorsa manyetik rezonans görüntülemeler de kullanılır, pisiform kemik iliği içerisindeki ödem kırığın göstergesidir.

\section{Ulna stiloid kırığı}

Distal radyoulnar eklemin stabilitesi, radius sigmoid çentik, ulna başı ve eklemi bir arada tutan bağlar sayesinde sağlanır. Bağlar foveadan ve stiloidin tabanından distal radius sigmoid çentik kenarlarına uzanır. Ulnoradyal bağ, distal radyoulnar eklem için, dorsalpalmar yöndeki ana stabilizatördür. ${ }^{[13]}$ Direkt grafi temel tetkiktir.

\section{Triangular fibrokartilaj kompleks (TFKK) yaralanması}

Ulnar taraf ağrılı el bileği ve kapının kilidini açarken ağrının artması tipiktir. Fovea bulgusu (ulna stiloid ve fleksör karpi ulnaris tendonu arasında) pozitiftir (Şekil 2). Ulnar deviasyonda TFKK kompresyonu nedeni ile, radyal deviasyonda ise TFKK gerilimi nedeni ile ağrı artar.

Direkt grafiler sıklıkla bulgu vermez, ancak ulnar varyans hakkında yorum yapılabilir. Artrografiler eklemde kontrast maddenin dışa taştığını gösterdiğinde tanı koydurur, ancak manyetik rezonans görüntüleme artrografinin yerini almıştır. Lunat kemiğin ulnar tarafindaki yırtıklar ulnokarpal impaksiyon göstergesidir. Tanıda en kesin bilgiyi veren tetkik el bilek artroskopisidir. Haftalar ve aylar süren splintleme ve aktivite modifikasyonuna rağmen ilerleme kat edilemeyen hastalarda el bilek artroskopi endikasyonu vardır.

\section{Ulnar impaksiyon sendromu/Ulnolunat abutment/ Ulnokarpal abutment sendromu}

Ulna ve karpaller, özellikle de lunat kemik arasındaki strestir. Ulnar varyans pozitiftir. Ballotman testi, Nakamura ulnar stres testi, fovea testi pozitiftir. El bileği nötralde iken ulnar varyans değerlendirilmesi için direkt grafi temel tetkiktir. Lunat kemikte ve ulna başında skleroz gözlenebilir. Artrografiler eşlik eden TFKK yırtığı ve lunotrikuetral yırtığını gösterebilir. Manyetik rezonans görüntüleme, TFKK yaralanmalarını değerlendirmede kullanılabilir. ${ }^{[2,14]}$

\section{Ulnar stiloid impaksiyon sendromu}

Ulna stiloid ucu ile trikuetrum arasındaki impaksiyondur. Stiloid ve TFKK boyunca hassasiyet mevcuttur.
Ağrı nedeni ile hareket açıklığı kısıtlanmıştır. Maksimum ulnar deviasyon ve aksiyel yüklenme altında supinasyondan pronasyona rotasyonlar semptomları ortaya çıkarır. ${ }^{[15,16]}$ Direkt grafilerle ulnar varyans, subkondral kistler değerlendirilir. Manyetik rezonans görüntüleme, TFKK ve lunotrikuetral bağın değerlendirilmesine yardımcıdır.

\section{Pisotrikuetral artrit}

Pisiformu iki parmak arasında tutup dorsale bastırırken radyoulnar plandaki hareket ile ağrı meydana gelir. Bu teste ek olarak tanıda direkt grafiler yardımcıdır. Pisotrikuetral artrit eklem kartilajlarının kronik dejeneratif hastalığıdır. Yarı supinasyondaki oblik grafiler pisotrikuetral eklemdeki osteoartriti ve fleksör karpi ulnaris entezopatisini gösterebilir. ${ }^{[17]}$ Ultrasonografi, bilgisayarlı tomografiler, manyetik rezonans görüntüleme nadiren gerekir. ${ }^{[18]}$

\section{Ekstansör karpi ulnaris (EKU) subluksasyonu}

Altıncı dorsal kompartman üzerinde ağrı, tendinite bağlı şişlik olabilir ve atlama hissi alınır. EKU tendonu supinasyonda disloke olurken, pronasyonda yerine gelir. EKU subluksasyonunu test etmek için, ön kol supinasyona ve bilek ulnara deviye edilir, bu esnada tendon gözlemlenir ve ulnar, volar subluksasyonu değerlendirmek için palpe edilir (Şekil 3).

\section{Lunotrikuetral (LT) instabilite}

Hipotenar temas noktasıyla dorsifleksiyonda olan el bileği üzerine düşme öyküsü, ulnar taraflı instabilite şüphesini artırmalıdır. Dorsalden uygulanan kuvvetler, ulnar pozitif varyans ve perilunat/ters perilunat yaralanma ile birlikte görülebilir. Hastalar ulnar taraflı bilek ağrısı ve azalan kavrama gücünden şikâyetçidir. LT eklemde ağrı ve hassasiyet vardır. Bu bölge ulna dorsal çıkıntısının distalinde trikuetrum tüberkülü palpe edilerek kolayca bulunabilir. Ağrı genellikle ön kol supinasyonu ve el bileğinin ulnar eğimi ile şiddetlenir. İlerlemiş olgularda ön kola oranla el bileği ulnarının subluksasyonu olabilir. Daha önce de tanımlandığı gibi provokatif testlerle semptomlar artırılabilir. ulnar deviasyon ve pronasyonda atlama sesi alınabilir. Bir başka tanısal manevra, kortikosteroidin LT artikülasyonuna veya ulnar midkarpal boşluğa enjekte edilmesini içerebilir. ${ }^{19]}$

\section{Dissosiyatif olmayan karpal instabilite}

Radius ile proksimal karpal sıra veya proksimal sıra ile distal karpal sıra arasındaki ilişkide semptomatik bir bozulmanın ortaya çıktığı bir patolojidir. Aynı sıra içindeki kemikler arasındaki ilişki korunmuştur. El bileği ulnar deviasyona alınırken önce proksimal karpal sıradaki ani ekstansiyona gelişe bağlı "clunk" alınırken el bileğine uygulanan ulnar deviasyon artırıldıkça 
kapitatın dorsale subluksasyonu hissedilebilir. Bu hastalarda radyal deviasyonda proksimal sıranın fleksiyona gelişinde de bozulma gelişebilir. Genellikle global laksite mevcut olan erişkin çağda görülür. Dinamik bir instabilite olduğu için değişen derecelerde radyal ve ulnar deviasyonda stres grafileri tanıda değerlidir. ${ }^{[20]}$

\section{Radyokarpal ve Midkarpal Enjeksiyonlar}

Enjeksiyonlar tanı koymaya yardımcıdır; örneğin kronik el bileği ağrısı olan normal radyografilere sahip hastalarda intrakarpal patolojilerin ayırt edilmesinde midkarpal lidokain enjeksiyonları yararlıdır. Literatürde bu hastalarda \%28'e varan kavrama kuvvetinde iyileşme gözlenmiştir. ${ }^{[21]}$ Radyokarpal enjeksiyonlar da TFKK ya da radyokarpal eklem patolojilerinde ağrıyı azaltır. Enjeksiyonlar olası cerrahinin başarısını tahmin etmede de kullanılabilir, ancak enjeksiyonlar ile ağrısı azalmayan hastaların cerrahiden de yarar görmeyeceği söylenemez.

\section{SONUÇ}

Pek çok hastalık ve klinik tablo, ulnar taraflı el bileği ağrılarının sebebi olabilir. Bu ayırıcı tanının yapılmasında anamnez ve herkesçe kabul edilmiş genel el ve el bileği muayenesinin yanında özgül testlerin bilinmesi ve yapılması gerekir. Görüntüleme yöntemleri de buna eşlik ederek en üst yararı sağlar.

\section{KAYNAKLAR}

1. Sachar K. Ulnar-sided wrist pain: evaluation and treatment of triangular fibrocartilage complex tears, ulnocarpal impaction syndrome, and lunotriquetral ligament tears. J Hand Surg Am 2012;37(7):1489-500. Crossref

2. Vezeridis PS, Yoshioka H, Han R, Blazar P. Ulnar-sided wrist pain. Part I. anatomy and physical examination. Skeletal Radiol 2010;39(8):733-45. Crossref

3. Yildiran G, Sutcu M, Akdag O, Isik C, Tosun Z. Role of Active Range of Motion in Hand and Wrist Joint Photography: A Preliminary Analysis. Ann Plast Surg 2019;82(6):636-8. Crossref

4. Tay SC, Tomita K, Berger RA. The "ulnar fovea sign" for defining ulnar wrist pain: an analysis of sensitivity and specificity. J Hand Surg Am 2007;32(4):438-44. Crossref
5. Fontaine C. Kienböck's disease. Chir Main 2015;34(1):4-17. Crossref

6. Schuind F, Eslami S, Ledoux P. Kienbock's disease. J Bone Joint Surg Br 2008;90-B(2):133-9. Crossref

7. Slutsky DJ, Nagle DJ. Wrist arthroscopy: current concepts. J Hand Surg Am 2008;33(7):1228-44. Crossref

8. Skirven T. Clinical examination of the wrist. J Hand Ther 1996;9(2):96-107. Crossref

9. Nakamura R, Horii E, Imaeda T, Nakao E, Kato H, Watanabe $K$. The ulnocarpal stress test in the diagnosis of ulnar-sided wrist pain. J Hand Surg Br 1997;22(6):719-23. Crossref

10. Sevenoaks H, Khan SH, Younis F. Diagnosis of ulnar-sided wrist pain: a pragmatic approach for the non-specialist. $\mathrm{Br} \mathrm{J}$ Hosp Med (Lond) 2019;80(8):456-60. Crossref

11. Butterfield $W L$, Joshi $A B$, Lichtman $D$. Lunotriquetral injuries. $J$ Hand Surg Am 2002;4(2):195-203. Crossref

12. DaSilva MF, Goodman AD, Gil JA, Akelman E. Evaluation of Ulnar-sided Wrist Pain. J Am Acad Orthop Surg 2017;25(8):e150-6. Crossref

13. Logan AJ, Lindau TR. The management of distal ulnar fractures in adults: a review of the literature and recommendations for treatment. Strategies Trauma Limb Reconstr 2008;3(2):4956. Crossref

14. Dickson LM, Tham SK. Osteotomy for sigmoid notch obliquity and ulnar positive variance. J Wrist Surg 2014;3(1):50-4. Crossref

15. Sammer DM, Rizzo M. Ulnar impaction. Hand Clin 2010;26(4):549-57. Crossref

16. Tomaino MM, Elfar J. Ulnar impaction syndrome. Hand Clin 2005;21(4):567-75. Crossref

17. Kofman KE, Schuurman $A H$, Mulder MC, Verlinde SA, Gierman LM, van Diest PJ, Bleys RL. The pisotriquetral joint: osteoarthritis and enthesopathy. J Hand Microsurg 2014;6(1):18-25. Crossref

18. Blum AG, Zabel JP, Kohlmann R, Batch T, Barbara K, Zhu X, Dautel G, Dap F. Pathologic conditions of the hypothenar eminence: evaluation with multidetector $C T$ and MR imaging. Radiographics 2006;26(4):1021-44. Crossref

19. Wagner ER, Elhassan BT, Rizzo M. Diagnosis and treatment of chronic lunotriquetral ligament injuries. Hand Clin 2015;31(3):477-86. Crossref

20. Wolfe SW, Garcia-Elias M, Kitay A. Carpal Instability nondissociative. J Am Acad Orthop Surg 2012;20(9):575-85. Crossref

21. Bell SJ, Hofmeister EP, Moran SL, Shin AY. The diagnostic utility of midcarpal anesthetic injection in the evaluation of chronic wrist pain. Hand (N Y) 2007;2(2):39-45. Crossref 